\title{
La Prueba en la Acción Inhibitoria (Trabalho escrito para a coletânea publicada em homenagem ao Prof. Hernando Devis Echandía)
}

\author{
Luir Suilherme OMarinoni
}

Profesor Titular de La Cátedra de Derecho Procesal Civil de La Universidad Federal del Paraná, Abogado.

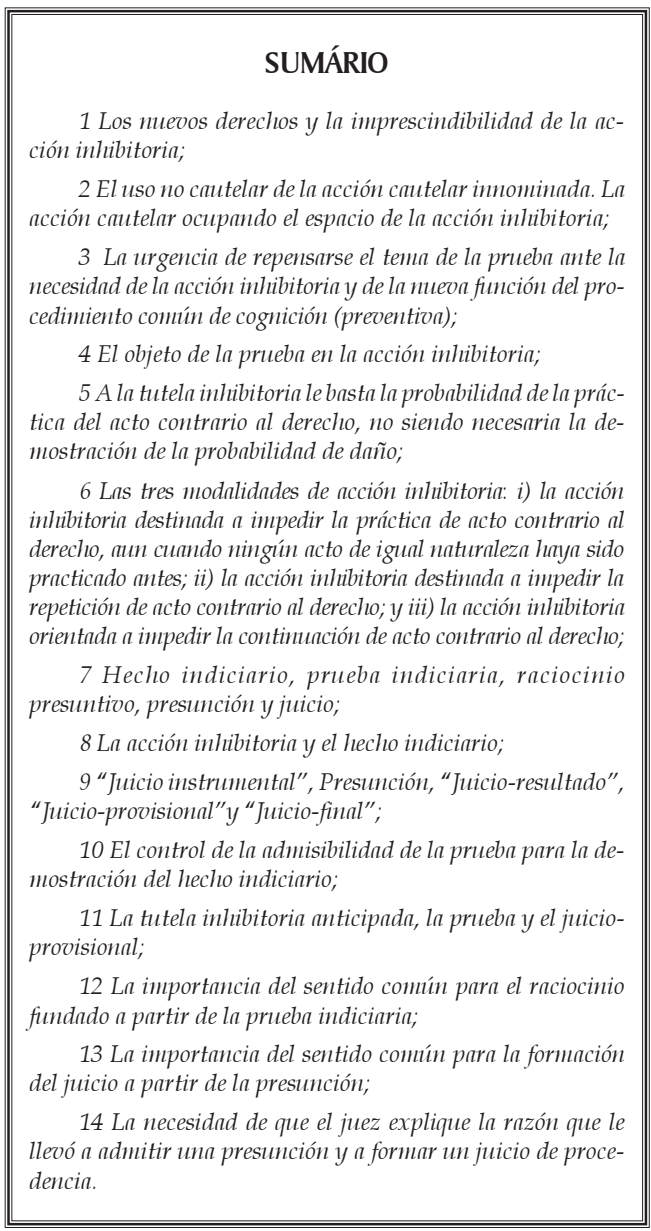

\section{Los nuevos derechos y la imprescindibilidad de la acción inhibitoria}

$\mathbf{E}$

n la sociedad contemporánea existen una serie de derechos de contenido no patrimonial. Estos derechos son típicos de la sociedad actual, en que se adquiere una conciencia cada vez más nítida de la necesidad de su efectiva consagración como bienes imprescindibles para la vida digna de las personas.

Los derechos de contenido no patrimonial son derechos inviolables. De la misma manera, algunos derechos, como el derecho a una marca comercial, aun teniendo contenido patrimonial, importan cuando no violados, es decir, dependen para que sean disfrutados adecuadamente de la inviolabilidad de terceros. Derechos de este porte no se concilian con el resarcimiento pecuniario, incluso porque el uso exclusivo de determinada marca comercial (por ejemplo) puede ser crucial para el suceso de una actividad. 
Si tales derechos pueden estar amenazados de lesión, y si no les queda otra alternativa a aquellos que los poseen a no ser la de apelar a la "justicia" (Art. 5, XXXV, de la Constitución Federal brasileña), no hay cómo negar que se haga imprescindible hablar de un derecho de acceso a la justicia que tenga como corolario el derecho a la tutela preventiva.

Pero esto sólo no basta. Aunque el derecho a la tutela preventiva sea indiscutible, es necesario que la legislación procesal civil coloque a disposición de sus usuarios instrumentos procesales que realmente sean capaces de permitir la tutela preventiva.

Para esto, son necesarios procedimientos con técnica de anticipación, sentencias de características diferentes de aquellas que hacen parte de la tradicional clasificación trinaria, y medios de ejecución que puedan permitir la concretización de la tutela preventiva. ${ }^{1}$

\section{El uso no cautelar de la acción cautelar innominada. La acción cautelar ocupando el espacio de la acción inhibitoria}

Como se intuye, las propias necesidades sociales impusieron una nueva manera de utilizar el proceso civil. Fueron ellas, por ejemplo, ante la necesidad cada vez más evidente de tutela preventiva, las que indujeron al uso de la acción cautelar innominada como técnica de sumarización del proceso de conocimiento.

Como es sabido, el procedimiento de cognición clásico no contenía la tutela anticipatoria en su interior, y desembocaba apenas en una de las sentencias de la clasificación trinaria (declarativa, constitutiva y condenatoria).

Tal procedimiento no poseía la posibilidad de tutela anticipatoria porque la ejecución, según la doctrina clásica, solamente se podría comenzar después de acabado el proceso cognitivo, el cual era destinado a la averiguación de la existencia de los derechos. No sería posible la ejecución antes de acabada la fase de cognición porque no tendría cabimiento invadir la esfera jurídica del reo sin conferírsele a él amplia oportunidad de defensa.

Además, un proceso que solamente puede culminar en las sentencias declarativa, constitutiva y condenatoria, no tiene capacidad para impedirle a alguien violar un derecho.

Bien, quien pide sentencia declarativa se limita apenas a pedir declaración sobre una relación jurídica. El juez, en la sentencia declarativa, tiene su función limitada a la declaración, que le impide ordenar un no hacer o un hacer bajo pena de multa. El juez, en tal sentencia no interfiere en la esfera jurídica de lo particular; por esta razón se puede decir que la sentencia declarativa es la sentencia típica del derecho liberal clásico. 
A su vez, la sentencia condenatoria, como su propio nombre indica, "condena" como consecuencia de la violación de un derecho. Esta sentencia es evidentemente represiva, y es por esta razón que la sentencia condenatoria siempre se definió como aquella que tiene capacidad para abrir las puertas de la "ejecución forzosa", procedimiento que, como se sabe, permite la "realización forzosa de un derecho violado".

Como está claro, justamente porque los que concibieron el proceso de conocimiento clásico no se preocupaban con la preventividad, se idealizó un procedimiento sin la posibilidad de tutela anticipatoria y sin sentencia idónea para permitir la prevención.

Bien, como el procedimiento diseñado para cumplir la función cautelar contenía la posibilidad de medida "liminar" y podía terminar en una sentencia que pudiera permitir la tutela preventiva, los operadores jurídicos rápidamente empezaron a utilizar esta vía para aquellas situaciones en que se necesitaba evitar solamente la violación de un derecho.

Es evidente que se escogió la vía (o el instrumento) pensado para cumplir la función cautelar para realizar la función preventiva apenas porque ésta última no podía ser ejercida a través del proceso cognitivo, el cual, conforme ya se ha dicho, fue ideado para realizar meramente funciones declarativa, constitutiva o condenatoria, sin importarse jamás con la tempestividad o la preventividad de la tutela de los derechos.

\section{La urgencia de repensarse el tema de la prueba ante la necesidad de la acción inhibitoria y de la nueva función del procedimiento común de cognición (preventiva)}

Si el proceso civil es un instrumento para la adecuada tutela de los derechos, y si, siguiendo esta línea, el procedimiento constituye apenas una técnica para la perfecta y correcta realización del servicio jurisdiccional, es lógico que el procedimiento no se puede distanciar de los derechos que protege, y mucho menos de las nuevas necesidades de la sociedad contemporánea, bajo pena de no poder atender a los nuevos derechos y transformarse así en una especie de técnica inútil para alcanzar los fines que el Estado tiene por misión cumplir.

Para que el procedimiento pueda realizar la función preventiva - que es la función jurisdiccional más importante que el Estado puede realizar -, no basta apenas un procedimiento con auto de providencia anticipatoria en su íntimo y con sentencias que puedan dar oportunidad a la tutela preventiva. Es necesario, igualmente, que el instituto de la prueba civil sea repensado, imaginándose la afirmación de alguien que teme la violación de un derecho, o mejor, la de alguien que teme la práctica de un acto ilícito. ${ }^{2}$

2 "Verificando el legislador o el magistrado que la prueba para determinado hecho es muy difícil o especialmente sacrificante, podrá valerse de la idea de presunción para construir un raciocinio capaz de conducirle a la conclusión de la ocurrencia del hecho, por la verificación del contexto en que normalmente incidiría aquel hecho. Como se puede observar, este poderoso instrumento es un 
Si el proceso de conocimiento fue idealizado como un proceso orientado hacia el pasado está claro que el tema de la prueba fue pensado para permitir la formación de un juicio acerca de un hecho ocurrido, es decir, de un hecho pasado. Cuando se piensa en un hecho que puede ocurrir, o en un hecho futuro, está en el pasado apenas el hecho que indica que posiblemente lo ilícito se practicará.

\section{El objeto de la prueba en la acción inhibitoria}

En la acción inhibitoria, conforme a lo explicado, una acción destinada a evitar la práctica del acto futuro que configure una violación de derecho, lo que importa es la concreta probabilidad de la práctica de un acto ilícito. Así, es necesario verificar no sólo la probabilidad de la práctica del acto sino también si tal acto configura ilícito.

Con relación a la cuestión para saberse si el acto que se teme es ilícito, exige el confronto entre la descripción del acto temido y el derecho, constituyendo una "cuestión de derecho".

El gran problema, como inmediatamente se puede percibir, es el de la prueba que recae en la afirmación de que probablemente se practicará un acto. Pensando en la prueba de esta afirmación, alguien podría imaginar dos hipótesis distintas: i) la prueba del hecho pasado que demuestra la probabilidad de que un acto será practicado y ii) la prueba de que un hecho futuro ocurrirá.

La segunda hipótesis parece ser inviable, porque no puede haber prueba que incida sobre determinado hecho que todavía no ocurrió; lo que puede existir es la prueba de un hecho pasado que indique la probabilidad de la ocurrencia de un hecho futuro.

En tal caso existiría un hecho indiciario (o indicio), una prueba a la que se le puede llamar de indiciaria, y a la que se le exigiría una forma de raciocinio que se puede llamar de presuntiva, la cual parte de la alegación de un hecho indiciario (o indicio) y de una eventual prueba indiciaria para llegar al juicio acerca de la afirmación de la probabilidad de la práctica de un acto ilícito.

Es posible que el reo no niegue que practicará el acto, pero que afirme que éste no tendrá la naturaleza o la extensión del acto vedado por la normativa legal. En este caso, tratándose de una acción orientada a impedir la repetición o la continuación de lo ilícito, basta verificar si el acto anteriormente practicado realmente se encuadra en la prohibición legal. Más difícil será la prueba de ilicitud si acto "igual"no se ha practicado todavía. En tal hipótesis, se tendrá que demostrar que el acto que se pretende practicar está realmente vedado por la normativa legal, y de esta manera deberá

importante aliado del proceso para la prueba de los hechos en los que sea difícil su verificación o de eventual ocurrencia (como los hechos futuros, en el caso de acciones inhibitorias)" (Luiz Guilherme Marinoni y Sérgio Cruz Arenhart, Comentarios ao Código de Processo Civil, São Paulo, Ed. RT, 2000, v. 5, tomo 1, p. 135). 
esclarecerse lo siguiente: ¿ el acto que será practicado se encuadra en la moldura legal que lo prohíbe?

Obsérvese que en las situaciones en las que se discute apenas la extensión y la naturaleza del acto que estaría siendo negado como ilícito, la prueba no tendrá como objetivo demostrar un hecho indiciario que indique la probabilidad de la práctica de un ilícito sino evidenciar que el acto que se pretende practicar es ilícito.

\section{A la tutela inhibitoria le basta la probabilidad de la práctica del acto contrario al derecho, no siendo necesaria la demostración de la probabilidad de daño}

Durante largo tiempo, se pensó que el proceso civil debería preocuparse únicamente con lo ilícito dañoso, o quizás mejor, con el acto ilícito que estuviese constituido por una situación dañosa. Se sobrentendía, en otras palabras, que el proceso civil era destinado apenas a tratar del daño.

Con el paso de los años y con el establecimiento de la sociedad contemporánea, se verificó que innúmeros actos contrarios al derecho, aun cuando no produciendo efectos dañosos, no podrían permanecer alejados del proceso civil. Este último, para la adecuada vida en sociedad, tendría que utilizarse para su reprensión o prevención.

Se concluyó, de esta manera, que el acto ilícito es sólo el acto contrario al dere- cho, mientras que el daño es su consecuencia eventual.

Cuando la acción fuera destinada a reparar el daño, sería necesario, dejando de lado los casos de responsabilidad objetiva, el llamado elemento subjetivo. Nadie puede ser condenado a reparar un daño, excepto en las hipótesis excepcionales ya repasadas, si no se actúa por lo menos con culpa.

Sin embargo, en la acción dirigida a corregir un acto ilícito ya practicado, en el que no se desea reparar un daño, se exime a la culpa. Así, queda claro que el daño y la culpa no constituyen presupuestos de la tutela inhibitoria. En la acción inhibitoria es suficiente la demostración de la probabilidad de acto contrario al derecho, ya que el daño es la consecuencia eventual y el elemento subjetivo es apenas el criterio para la imputación de la responsabilidad resarcitoria.

Muchas veces, por una cuestión meramente cronológica, el daño se produce en el mismo momento en el que el acto contrario al derecho se practica. Sin embargo, en tales casos, e incluso cuando el daño pueda ocurrir después de practicado el acto contrario al derecho, nada impide que se demuestre que un daño se produjo, y que por lo tanto es justo el temor a su reiteración o continuación, o que existen otros hechos que son suficientes para que se tenga la convicción de que posiblemente un daño se practicará.

No obstante, no es porque la tutela inhibitoria pueda evitar la práctica de un daño que el actor será obligado a demos- 
trar la probabilidad de su ocurrencia; en estos casos, bastará la demostración de la probabilidad de la práctica del acto contrario al derecho. Pongamos un ejemplo: si el actor de una acción colectiva inhibitoria quiere evitar la venta de productos nocivos a la salud del consumidor, basta que se demuestre que la posible venta constituirá acto contrario al derecho, porque no está de acuerdo con la normativa legal; lo que está en cuestión es únicamente la probabilidad de la venta del producto. No se necesitará demostrar que el comprador posiblemente perjudicará su salud en el caso de que consuma el producto. Queda claro que la acción inhibitoria, no se dirige contra la mera posibilidad de daño, y por esta razón nadie podrá pensar que la referida acción colectiva inhibitoria tenga naturaleza cautelar, y que se deba por lo tanto seguir de una "acción principal".

Si embargo, lo que más importa, cuando se habla de que la acción inhibitoria se dirige apenas contra el acto contrario al derecho, es que el juez no puede exigir la demostración de la probabilidad de daño en el proceso, en el que, como en el ejemplo narrado, lo que se objetiva solamente es evitar la práctica de acto contrario al derecho.

Obsérvese que es mucho más simple, del punto de vista probatorio, demostrar que probablemente ocurrirá la venta de un producto, que demostrar que este producto es perjudicial para la salud del consumidor. Este último juicio, o sea, el juicio con respecto a la nocividad del producto, ya lo ha hecho el legislador que editó la norma que veda su venta.

\section{Las tres modalidades de acción inhibitoria: i) la acción inhibitoria destinada a impedir la práctica de acto contrario al derecho, aun cuando ningún acto de igual naturaleza haya sido practicado antes; ii) la acción inhibitoria destinada a impedir la repetición de acto contrario al derecho; y ii) la acción inhibitoria orientada a impedir la continuación de acto contrario al derecho}

Aunque la acción inhibitoria, al contrario de la acción represiva, siempre esté dirigida hacia el futuro, al actor le es mucho más fácil demostrar que teme a la violación de su derecho cuando la acción se destina a impedir la repetición o la continuación del acto contrario al derecho, de que cuando la acción se dirige a impedir la práctica de ilícito, aun cuando ningún acto de esta naturaleza se haya practicado.

Cuando se teme la repetición de ilícito, la prueba de que el reo ya ha practicado un acto del mismo porte es prueba de hecho indiciario lo que permite un raciocinio presuntivo capaz de formar una conclusión de que probablemente será cometido un acto igual. Tratándose de una acción dirigida a impedir la continuación del ilícito, la formación de juicio de procedencia también es facilitado, importando que se demuestre que ya se ha cometido un acto contrario al derecho. 
En la modalidad de acción inhibitoria que todavía nos queda - que no tiene por objetivo el de evitar la simple repetición o la continuación de ilícito - solamente es posible la demostración del hecho distinto del que se teme, aunque tal hecho deba ser un indicio capaz de formar un juicio favorable al actor. Así, por ejemplo, temiéndose la divulgación de una noticia lesiva a la personalidad jurídica, constituirá relevante indicio, capaz de formar un juicio de procedencia, la divulgación del anuncio, por parte de determinada cadena de televisión, de que será divulgada la noticia. Tal prueba indiciaria es un medio relevante para demostrar que probablemente la noticia será divulgada; otra cuestión, como es obvio, es saber si esa divulgación constituirá acto ilícito.

\section{Hecho indiciario, prueba indiciaria, raciocinio presuntivo, presunción y juicio}

No es rara la confusión entre hecho indiciario, prueba indiciaria, raciocinio presuntivo, presunción ${ }^{3}$ y juicio. Como tales conceptos son importantes para comprender mejor el tema de la prueba dentro del proceso civil, son importantes algunas consideraciones, aunque sean breves, para distinguirlos.

El hecho indiciario, sólo se puede comparar al hecho principal. Es que el he- cho indiciario, al que también se le llama de indicio, es al igual que el hecho principal, un mero hecho. Cuando se alega este hecho, se debe demostrar a quien lo juzga que la prueba será importante para la formación de un juicio de procedencia.

El indicio no es la prueba. La prueba indiciaria, como en cualquier tipo de prueba, recae sobre una afirmación de hecho. ${ }^{4}$ La peculiaridad de la prueba indiciaria está en que recae en un hecho que es indiciario, es decir, sobre un indicio.

Por consiguiente, es necesario recalcar la diferencia de los conceptos de hecho indiciario, la prueba destinada a demostrarlo - llamada de prueba indiciaria -, y raciocinio presuntivo, que es el medio por el cual aquél que juzga raciocina para que, a partir de un hecho indiciario, se llegue a una presunción. ${ }^{5}$ Explicándolo mejor: el juez a partir de una alegación de hecho (hecho indiciario) y de su prueba, raciocina (de forma presuntiva) para llegar a una conclusión (presunción).

Sin embargo, la presunción no se confunde con el "juicio final" (propio de la sentencia), ya que puede haber, por ejemplo, la presunción de que un acto será practicado, pero la prueba de que tal acto no constituirá ilícito, En este caso el "juicio final" y, por tanto, la sentencia, serán de improcedencia.

3 Sobre el tema de las presunciones, ver, en el derecho brasileño, José Carlos Barbosa Moreira, As presunções e a prova, Temas de direito processual, $1^{\text {a }}$ serie, São Paulo, Saraiva, 1998, p. 55 y ss; João Batista Lopes, A prova no direito processual civil, São Paulo, Ed. Revista dos Tribunais, 1999, p. 59 y ss.

4 Con relación a los hechos relevantes, se realiza una afirmación y le cabe al juez determinar si ésta, según las pruebas producidas principalmente, es verdadera o falsa. En este sentido, se dice que lo que se prueba es la afirmación de un hecho, y no un hecho.

5 Por lo tanto, la presunción es la conclusión del raciocinio presuntivo. 
Es interesante percibir, por ejemplo, que en determinado caso concreto se pueden alegar y probar tres hechos indiciarios, y realizarse tres raciocinios presuntivos que apunten hacia tres presunciones. La cuestión que surge con relación a esto es la de saber si, en tal caso, realmente es mejor referirnos a tres presunciones, o a una presunción que se forma a partir de las pruebas de los tres hechos indiciarios. Es mejor hablar de tres presunciones, visto que cada prueba de hecho indiciario conduce a una conclusión y que la suma de estas conclusiones nos lleva a otra, que es el "juicio final" propio de la sentencia. En este caso, se puede decir que una determinada presunción no es suficiente para un juicio de procedencia, pero que basta la suma de esta presunción con otra para que se tenga una sentencia favorable al actor.

\section{La acción inhibitoria y el hecho indiciario}

Quien pide la tutela inhibitoria alega temer la práctica de acto contrario al derecho. Así, tendrá que demostrar la probabilidad de que un acto ilícito se vaya a practicar. Para demostrar tal probabilidad debe alegar hechos que sean suficientes para permitirle al juez, raciocinando, formar un juicio acerca de la alegación de que probablemente será practicado un ilícito.

Considerándose apenas la demostración de la probabilidad del acto afirmado ilícito (la ilicitud del acto temido no se discute), se deben alegar hechos que, una vez hayan sido demostrados, puedan conducir al juez a concluir que probablemente se practicará la violación del derecho. Tales hechos son indiciarios.
Cuando el hecho sirve apenas para permitirle al magistrado, a través de su raciocinio, establecer una conclusión presuntiva, el hecho es indiciario. Es por esta razón que el hecho pasado, en la acción inhibitoria, es un hecho indiciario destinado a demostrar la probabilidad de la práctica del acto futuro.

\section{9 "Juicio instrumental", Presunción, "Juicio- resultado", "Juicio- provisional"y "Juicio-final"}

El juicio constituye una conclusión, y en este sentido la conclusión a la que llega el juez después de haber ejercido una determinada actividad. En otras palabras, para que el juez forme un juicio, es necesario que raciocine, $\mathrm{o}$ sea, es indispensable un raciocinio.

El “juicio-final” es la última parte del raciocinio de quien juzga, en que se llega a un resultado sobre la pretensión del actor.

Se habla de "juicio-final" para distinguir el juicio acerca de la pretensión del actor y aquél que se puede formar, por ejemplo, con relación a un pedido de tutela anticipatoria (cuando es posible hablar de "juicio-provisional”). En este último caso, como es obvio, hay un juicio también, pero es incorrecto pensar en un "juicio-final".

Para que el juez forme un "juicio-instrumental", a saber, un juicio cuyo objetivo permita la formación de otro juicio, también es necesario evidentemente raciocinio.

Para la formación del "juicioresultado"("juicio provisional”o "juicio final”), el magistrado deberá analizar, por ejemplo, las pruebas producidas. El juicio 
que el magistrado hace para admitir una prueba pericial (por ejemplo), es un "juicio-instrumental", ya que se realiza para permitir la correcta formación del "juicioresultado".

Sin embargo, el "juicio-resultado"requiere del análisis de "juicios menores" formados a partir de pruebas, o sea, exige la valoración de las presunciones. Como la presunción parte también de una prueba, se puede decir que el "juicio-presunción” pasa también por un "juicio-instrumental", pero que sirve para la formación de un juicio mayor, que es el "juicio-resultado".

En resumen: el "juicio-resultado", que se puede asentar en la presunción, es el género del cual son especies el "juiciofinal"y el "juicio-provisional", mientras que el "juicio instrumental" es el que se forma para llegarse a un dato que es instrumental.

\section{El control de la admisibilidad de la prueba para la demostración del hecho indiciario}

Si la presunción es fundamental para la formación del "juicio-resultado"en la acción inhibitoria, es necesario verificar la distinción entre la cuestión de admisibilidad de la prueba destinada a demostrar el hecho indiciario y el problema de la correcta formación del juicio a partir de la presunción. En este ítem nos referiremos a la primera cuestión, mientras que la segunda la analizaremos en el ítem 13.

Es importante subrayar que el hecho indiciario no precisa alegarse. En la acción inhibitoria basta la alegación de que se teme un probable acto ilícito. No existe la carga del actor alegar los hechos que indiquen que probablemente será practicado lo ilícito. Esto no quiere decir que, evidentemente, no sea aconsejable que el actor especifique los hechos que apuntan para la probabilidad de que lo ilícito sea practicado. Es preciso dejar claro, solamente, que el actor puede requerir la producción de la prueba en relación con un hecho meramente indiciario, aunque no se le haya solicitado oportunamente al juez.

Es necesario verificar si el hecho que se intenta demostrar por medio de la prueba indiciaria es un hecho pertinente y relevante para la definición del mérito.

El hecho indiciario es pertinente cuando tiene relación con el acto temido, mientras que será relevante cuando, una vez que se haya demostrado, sea capaz efectivamente de evidenciar la probabilidad de que el acto se practique, y así influenciar en el juzgamiento del mérito.

Verificándose que de nada sirve pro barse el hecho indiciario, una vez que no tiene relación alguna con el acto temido, el juez deberá denegar la producción de la prueba indiciaria.

Si el hecho probandum no puede derivar del hecho que se pretende demostrar a través de la prueba indiciaria, esa prueba lógicamente deberá denegarse. Sin embargo, si el hecho indiciario apunta hacia varios hechos, entre los cuales el hecho probandum, la prueba indiciaria no podrá denegarse. En verdad, la presunción que se puede formar a partir de esta prueba mere- 
cerá menos credibilidad; el problema pasa a ser de valoración de la presunción para la formación del juicio, y no la de admisión de la prueba.

\section{La tutela inhibitoria anticipada, la prueba y el juicio-provisional}

Es importante dejar claro que la tutela es el bien de la vida que se busca a través del procedimiento, de la sentencia y de los medios de ejecución, que solamente son técnicas predispuestas por el legislador para la adecuada realización de la tutela jurisdiccional.

En este sentido, es evidente que la tutela se puede realizar al final del procedimiento o en el curso del mismo. En el primer caso existe lo que se puede llamar de "tutela final", mientras que en la otra hipótesis existe lo que se denomina de "anticipación de la tutela".

El CPC brasileño, en el artículo 273, al tratar específicamente de la "tutela anticipatoria”, afirma que el juez podrá anticipar, total o parcialmente, los efectos de la tutela, siempre que "existiendo prueba inequívoca, se convenza de la verosimilitud de la alegación".

Cuando se habla de anticipación de la tutela, se piensa en una tutela que se debe realizar en un tiempo menor del que será necesario para el término del procedimiento. Como el principal responsable por el dispendio de tiempo en el proceso es la producción de la prueba, muchas veces se admite la anticipación de la tutela antes de que las pruebas requeridas por las partes hayan sido producidas. En este sentido, se afirma que la tutela se concede con postergación a la producción de la prueba, o con la postergación de lo contradictorio. En estos casos, "prueba inequívoca" solamente puede significar la prueba formalmente perfecta, cuyo tiempo de producción no es incompatible con la inmediatez con que la tutela debe concederse.

Explicándolo mejor, la prueba no puede llamársele de "prueba de verosimilitud" o "prueba de certeza". Cuando el procedimiento debe proseguir para que otras pruebas se produzcan, el juicio formado durante el curso del procedimiento se le debe llamar de "juicio provisional", designado, por el CPC brasileño, de "juicio de verosimilitud".

La prueba no puede calificarse de "prueba de verosimilitud"; es el juicio, formado a partir de la prueba, que se le llama (artículo 273, CPC brasileño), desde nuestro punto de vista equivocadamente, de “juicio de verosimilitud".

Decir que la prueba debe formar un “juicio de verosimilitud”, como preceptúa el mencionado artículo 273, es decir lo obvio. Porque toda prueba, esté finalizado o no el procedimiento, apenas puede permitir la formación de un "juicio de verosimilitud", cuando se parte de la concepción de que la verdad es algo absolutamente inalcanzable. ${ }^{6}$ Si por "juicio de verosimilitud"

6 "En lo que atañe a la cuestión de la valoración de la prueba, es necesario que el juez tenga en mente, acordándose de Voltaire, que las verdades históricas nunca pasan de mera verosimilitud. Calamandrei, refiriéndose a una asertiva de Wach, advirtió que cuando se dice que un hecho es verdadero, se afirma, en sustancia, que él alcanzó en la conciencia de quién así lo juzga, el 
se entiende como juicio no formado sobre la base de la plenitud de las pruebas y argumentos de las partes, lo más correcto sería hablar de "juicio-provisional".

Sin embargo, lo más importante en este discurso es la demostración de que la diferenciación entre prueba y juicio ${ }^{7}$ no permite más que se hable de prueba de verosimilitud o juicio de verosimilitud cuando se hace alusión a un juicio provisional.

No existe verdad, ya que la verdad se encuentra en el campo de lo imposible. La verdad varia de acuerdo con la subjetividad de cada uno. La certeza sería la manifestación subjetiva de alguien, al respecto de un dato, de donde puede surgir la verdad para ella, pero no para los otros o para todos. Esta certeza - incluso porque la subjetividad del propio ser cognoscente puede mudar - no existe, o existirá, como absoluta, ni aquél que un día la afirmó. Toda certeza, por tanto, no pasa de mera verosimilitud. Pero el juez, no obstante, debe intentar encontrar, digámoslos así, la "certeza del caso concreto". (Luiz Guilherme Marinoni, Novas linhas do processo civil, São Paulo, Malheiros, 2000, p. 107/108, 4⿳亠丷厂 ed.).

\section{La importancia del sentido común para el raciocinio fundado a partir de la prueba indiciaria}

En el raciocinio presuntivo el juez parte de un hecho indiciario para llegar al hecho probandum. ${ }^{8}$

Como resulta obvio, el juez, no sólo al raciocinar así, sino también, al valorar la credibilidad de una prueba y su idoneidad para demostrar un hecho, se basa en su experiencia, que debe entenderse como la experiencia del hombre medio que vive en determinada cultura en cierto momento histórico.

En estos casos, el juez se ampara en el sentido común, y particularmente en lo que le interesa al raciocinio que puede dar origen a la presunción, al partir de un hecho indiciario para llegar al hecho principal, se vale de los conocimientos que deben estar fundados en aquello que comúnmente ocurre en la sociedad o que provienen de fuente idóneas y confiables.

Sería posible decir que el juez en tales hipótesis, se apoya en una "regla de experiencia”, que de acuerdo con el artículo

grado máximo de verosimilitud que, con relación a los medios limitados de conocimiento que el juzgador dispone, es suficiente para darle certeza subjetiva de que aquel hecho se verificó. Como dice Calamandrei, incluso al juez más atento y escrupuloso le vale el límite fatal de la relatividad que es propio de la naturaleza del ser humano, ya que lo que vemos es lo que parece que estamos viendo. Es por eso que todo el sistema probatorio civil es preordenado no solamente para permitir, sino verdaderamente para imponerle al juez para que se contente, al apreciar los hechos, con la verosimilitud.

7 Demostrando la diferencia entre prueba y juicio, así enseñaba el ilustre Devis Echandía: "El juez debe valorar o apreciar esas pruebas, de acuerdo con las reglas de la sana crítica, para saber cuál es la fuerza de la convicción que contienen y si gracias a ella puede formar su convicción sobre los hechos que interesan al proceso; pero ese acto del juez no es probatorio sino decisorio, puesto que se trata de adoptar la decisión que sea procedente". (Hernando Devis Echandía; Teoría General del Proceso, Buenos Aires, Editorial Universidad, 1997, p. 416.

Ver Luiz Gulherme Marinoni y Sérgio Cruz Arenhart, Manual do processo de conhecimento, São Paulo, Ed. RT, 2001. 
335 del CPC brasileño puede ser una "regla de experiencia común"o una "regla de experiencia técnica".

Por supuesto que, tratándose de una regla de experiencia técnica, ésta debe ser aquélla inherente al hombre común. En otras palabras, si el juez es licenciado en ingeniería civil o medicina, por ejemplo, no puede pretender formular concatenaciones tomando como base sus conocimientos técnicos personales. Hay que recordar que el juez que va a apreciar eventual recurso puede que no tenga este mismo conocimiento y que un conocimiento técnico puede ser discutible, es decir, que no esté sólidamente consagrado.

\section{La importancia del sentido común para la formación del juicio a partir de la presunción}

El juez evidentemente raciocina para formar su juicio a partir de una o más presunciones. En este caso, él se apoya también en el sentido común, tal como explícito en el ítem anterior.

Como resulta obvio, verificándose que la demostración del hecho indiciario no se realizó, no es posible establecer un raciocinio correcto a través de la presunción, para concluirse en el sentido de la procedencia de la pretensión inhibitoria; el raciocino judicial en este caso, será fallo, al tomar como premisa un hecho que no fue demostrado efectivamente.

Como ya hemos dicho, no es necesario que el hecho probandum sea la única consecuencia del hecho indiciario para que sea posible la formación del juicio de procedencia.

Si el hecho indiciario, una vez demostrado, puede colaborar para demostrar que probablemente el acto temido se practicará, la prueba indiciaria evidentemente puede sumarse a otra presunción para formar un juicio de procedencia.

Es preciso que quede claro que no es necesaria la suma de varias presunciones para la formación del juicio de procedencia; una única presunción, dependiendo del caso concreto, puede ser suficiente para establecer la convicción del juez a respecto de la procedencia del pedido. Sin embargo, al existir apenas una presunción, ésta debe ser capaz de formar un juicio de procedencia que pueda ser plenamente justificable; en otras palabras, se puede decir que, tratándose de apenas una presunción, el juez debe valorarla con extremado rigor. ${ }^{9}$

9 "Il requisito che ha creato forse più problemi interpretativi è quello della concordanza delle presunzioni semplici. In un'accezione più ristretta e rigorosa, diretta a porre un limite a discrezionalità del giudice in materia di prova presuntiva, si è affermato che la concordanza di più presunzioni è sempre indispensabile. Di conseguenza, non basterebbe una sola presunzione semplice a fornire la prova del fatto, poiché sempre occorrerebbero più presunzioni concordanti. In un'accezione meno rigida, e più orientata a far perno sul discrezionale convincimento del giudice, si ritiene invece che la presenza di più presunzioni concordanti non sia indispensabile, e quindi che la prova del fatto possa derivare anche de una sola presunzione semplice, purché essa sai abbastanza grave e precisa" (Comoglio, Luigi Paolo. Ferri, Corrado. Taruffo, Michele. Lezione sul processo civile, Pavia, II Mulino, 1995. p. 535). 
14 La necesidad de que el juez explique la razón que le llevó a admitir una presunción y a formar un juicio de procedencia

Se sabe que la motivación de las decisiones judiciales persigue explicar, racionalmente, las razones que llevaron al juez a concluir de una forma o de otra. Con su obligatoriedad, se intenta evitar el albedrío del juez.

De esta forma, se le obligará al juez a fundamentar la razón por la que deniega una prueba, el motivo por el que llega a una determinada presunción, las razones por las cuales cierta prueba o presunción le convencen de la procedencia del pedido etcétera.

La decisión del juez, en otras palabras, no debe sólo tener coherencia lógica, sino también contextual, importando los contextos del derecho y del sentido común. ${ }^{10}$

Es la fundamentación, anclada en la racionalidad, que justifica la presunción y el juicio de procedencia.

10 Cf. Michele Taruffo. Senso comum, experiência e ciência no raciocínio do juiz; Conferencia realizada en la Facultad de Derecho de la Universidad Federal del Paraná; Curitiba; 05.03.2001; p. 17. 